Manuelle Medizin 2012 $\cdot 50: 262-262$

DOI 10.1007/s00337-012-0945-0

๑) Springer-Verlag 2012

\author{
J. Buchmann · L. Beyer \\ Ärztevereinigung für Manuelle Medizin Ärzteseminar Berlin e.V., Berlin
}

\title{
Grußwort der ÄMM
}

aber präsentierst Du Dich in der ganzen Fülle dessen, was Manuelle Medizin vermag: manuelle Behandlung vor bzw. anstatt von Operationen insbesondere an der Wirbelsäule, manuelle Therapie nach Operationen, Manuelle Medizin bei Neugeborenen, bei Kindern, bei Sportlern, beim alten Menschen, bei Kreuzschmerz, bei Kopfschmerz, bei Tinnitus u.a.m. Dir ist es mit zu verdanken, dass die Manuelle Medizin zwar häufig „die alternative Methode“, nicht aber eine „andere Medizin“ ist, die neben der Schulmedizin einhergeht. Du bist ein Partner der manualmedizinischen Lehre in allen deutschsprachigen Ländern. Vor allem aber bist und bleibst Du ein Partner der täglichen Praxis, ein Partner, der im Laufe der Zeit beharrlich die Beweise zusammenträgt, die eine Erfahrungsmedizin hervorbringt und die in ihrer Gesamtheit so auch Kriterien einer evidenzbasierten Medizin erfüllen kann. Du sammelst die verschiedenen Gedanken, die aus individuellen Erfahrungen hervorgehen, die unterschiedliche Aspekte zu Biomechanik, Schmerzphysiologie, Muskelphysiologie, Motorik, Faszienverhalten oder zum Komplex der Neurophysiologie zeigen, die sich aber letztlich im konkreten Handeln am Patienten und im Therapieerfolg relativieren.

Neben Deinem Hauptjob, eine wissenschaftliche Zeitschrift zu sein, mit allen Ansprüchen an wissenschaftliche Publikationen, erfüllst Du auch hervorragend Deine zweite Aufgabe als Organ für aktuelle Mitgliederinformationen und als berufspolitisches Forum. Manchmal magst Du denken, „Emotionen sind die Triebkraft der Entwicklung “, manchmal magst Du Dir wünschen, noch von mehr Lesern zu erfahren, was sie bewegt und wo Du noch besser werden kannst.
Liebe Zeitschrift, liebe Verlagsredaktion, herzlichen Glückwunsch, weiter so! Wir bleiben Deine treuen Leser.

Im Namen des Vorstands und der Mitglieder der ÄMM

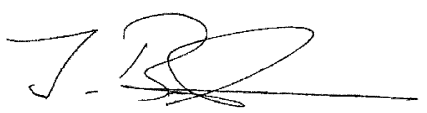

PD Dr. J. Buchmann

1. Vorsitzender ÄMM

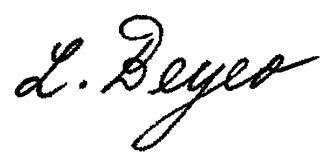

Prof. Dr. L. Beyer

Geschäftsführer ÄMM

\section{Korrespondenzadresse}

\section{Prof. Dr. L. Beyer}

Ärztevereinigung für Manuelle Medizin

Ärzteseminar Berlin e.V.

Köpenicker Str. 48/49, 10179 Berlin

lobeyer@t-online.de 